\title{
Location tracking using LoRa
}

\author{
Norlezah Hashim', Fakrulradzi Idris ${ }^{2}$, Tuan Nur Anisa Tuan Ab Aziz ${ }^{3}$, Siti Halma Johari', \\ Rozilawati Mohd Nor ${ }^{5}$, Norfariza Ab Wahab \\ ${ }^{1,3,4}$ Telecommunication Research and Innovation (CeTRI), Fakulti Teknologi Kejuruteraan Elektrik dan Elektronik \\ (FTKEE), Universiti Teknikal Malaysia Melaka (UTeM), Malaysia \\ ${ }^{2}$ Telecommunication Research and Innovation (CeTRI), Fakulti Kejuruteraan Elektronik dan Kejuruteraan Komputer \\ (FKEKK), Universiti Teknikal Malaysia Melaka (UTeM), Malaysia \\ ${ }^{5}$ Centre for Robotics and Industrial Automation (CeRIA), Fakulti Teknologi Kejuruteraan Elektrik dan Elektronik \\ (FTKEE), Universiti Teknikal Malaysia Melaka (UTeM), Malaysia \\ ${ }^{6}$ Centre of Smart System and Innovative Design (CoSSID), Fakulti Teknologi Kejuruteraan Elektrik dan Elektronik
} (FTKEE), Universiti Teknikal Malaysia Melaka (UTeM), Malaysia

\section{Article Info}

Article history:

Received Aug 7, 2020

Revised Nov 3, 2020

Accepted Dec 21, 2020

\section{Keywords:}

Arduino

GPS

IoT

LoRa

RSSI

\begin{abstract}
Local area network (LAN) as Bluetooth, WiFi and ZigBee are well established technology. The biggest problem with many LAN is the battery consumption and short ranges link budgets. LoRa is a new, private, unlicensed and spread spectrum modulation technique which allows sending low rates at extremely long ranges with minimal power consumption. More importantly, there is no access fee associated with this type of wireless technology. The main idea behind this work is to conduct performance and capability analysis of a currently available LoRa transceiver. We develop a location monitoring system using LoRa and global positioning system (GPS) module and we analyze the detectable range of its data, its battery consumption as well as received signal strength indicator (RSSI). Our deployment experiment demonstrates that the system is able to detect the transmitted data within 290 meters of distances. Using 6 volts of battery AA, the transmission of data still occurred after 24 hours. This project is emphasized a location monitoring system that provide low power usage but long range.
\end{abstract}

This is an open access article under the CC BY-SA license.

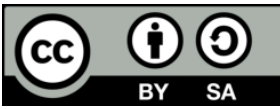

\section{Corresponding Author:}

Norlezah Hashim

Centre for Telecommunication Research and Innovation (CeTRI)

Fakulti Teknologi Kejuruteraan Elektrik dan Elektronik (FTKEE)

Universiti Teknikal Malaysia Melaka (UTeM)

Hang Tuah Jaya, 76100 Durian Tunggal, Melaka, Malaysia

Email: norlezah@utem.edu.my

\section{INTRODUCTION}

LoRa is a new, private, unlicensed and spread spectrum modulation technique which allows sending low rates data at extremely long ranges with minimum power consumption. More importantly, there is no access fee associated with this type of wireless technology. Local area network (LAN) as Bluetooth, WiFi and ZigBee are well established technology. The biggest problem with many LAN is the battery consumption and short ranges link budgets. Other than that, fundamentally mobile networks like LTE was developed for better data throughput but has disadvantage in term of power consumption. Both LAN and cellular network are quite expensive to deploy in a wide area for instance to cover a whole city. All these statements mentioned, a more efficient method is suggested to overcome these issues by using low power wide area network (LPWAN), LoRa. LoRa and the internet of things (IoT) have become the most important parts of 
modern telecommunications which need best in class battery life. LoRa needs very minimal cost for deployment at the same time it did not need to be licensed.

LoRa has been used in many health applications where many aimed for the long range communication for real time monitoring. Marco in [1] used LoRa to monitor and control the humidity of different rooms in order to reduce the costs of air conditioning operation. In [2] LoRa has been used to monitor the temperature of blood fridges inside a blood transfusion service. Reference [3] aimed to monitor air quality using different types of gas sensors. Meanwhile the author in [4] have developed a location tracking system without using global positioning system (GPS) but using multilateration algorithm on the gateways timestamps from received packages. From the applications mentioned, LoRa has great potential for universal applications especially for long range monitoring purposes. Dragino LoRa is used in many experimental research as mentioned in [5-10] but so far there is no analysis related to distances capability of LoRa transceiver while few researchers [11-17] focusses on improving the LoRa protocol. The authors in [18-20] proposed a mobile application and prototype smart home system based on LoRa.

By comparing to the previous works, this paper presents the development and analysis of location tracking system using LoRa module and GPS shield. The rest of this paper is organized as follows. Section 2 explain the research method used in this work. In section 3 the author discusses the result and discussions found in this work, and finally the work is concluded in section 4.

\section{RESEARCH METHOD}

The block diagram of the proposed diagram is shown in Figure 1. The system consists of two parts which are LoRa transmitter and receiver. LoRa/GPS shield was stacked onto Arduino at transmitter part before location data being transmitted on the LoRa network. At receiver part, LoRa shield was stacked onto Yun shield for data collection and then onto Arduino.

\subsection{Hardware and software component}

LoRa or global positioning system (GPS) shield with the part number of SX1276/SX1278 was used in the project. In this project, Arduino Mega was chosen as the microcontroller as it has more pins that can be used as an input or output compared to other version of Arduino. Yun shield was stacked between LoRa and Arduino, where the purpose of Yun shield is to solve the storage issue for Arduino board as this project require more storage to store GPS data. The transmitter and receiver parts were shown as Figures 2 and 3. Arduino IDE was used to develop the project.

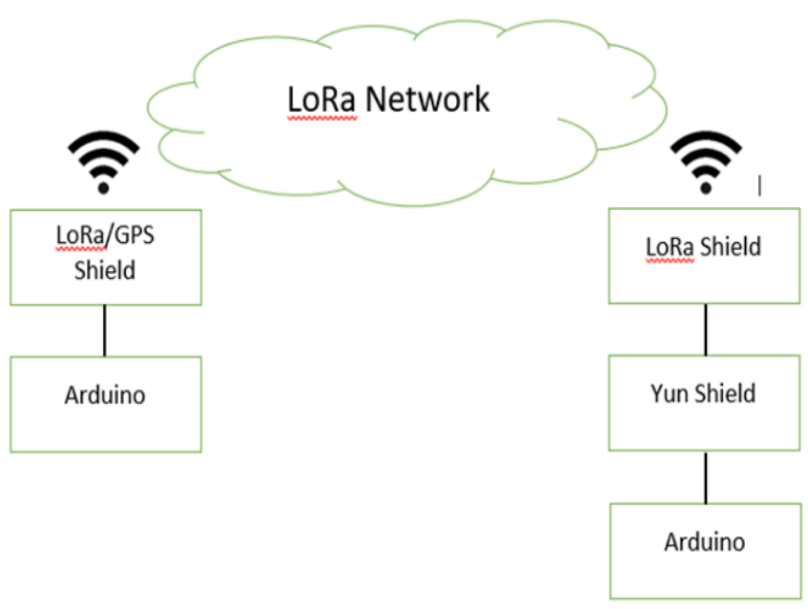

Figure 1. Block diagram of the proposed diagram

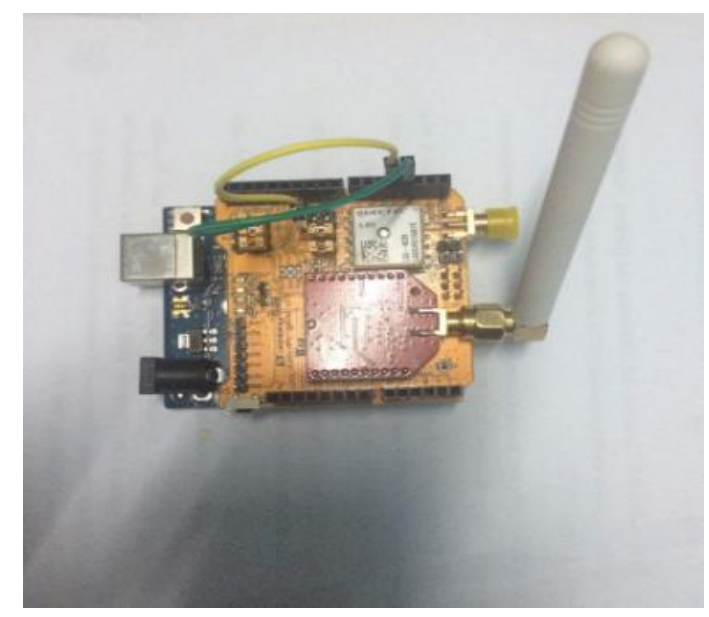

Figure 2. Transmitter

\subsection{Experiment setup}

Figure 4 shows how the experiment has been setup graphically before data was gathered and analyzed. Laptop was connected at each transmitter and receiver respectively while the serial monitor of each laptop will display the longitude and latitude data. 


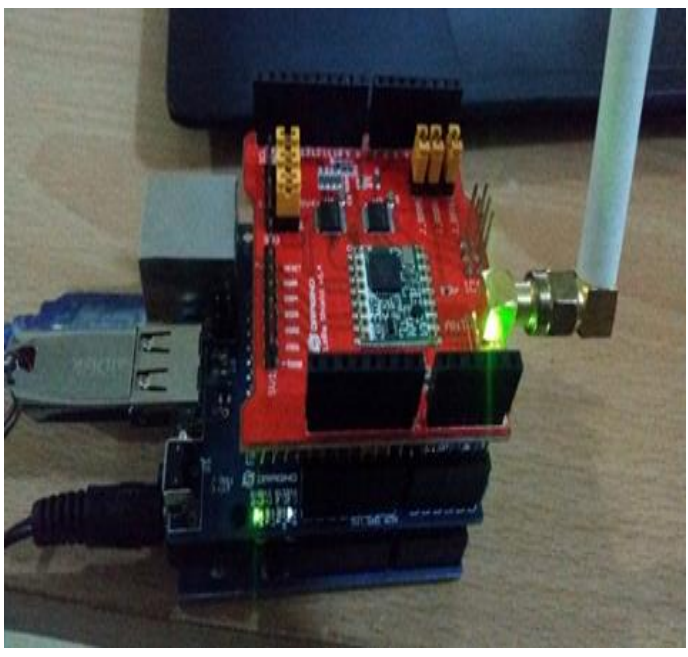

Figure 3. Receiver

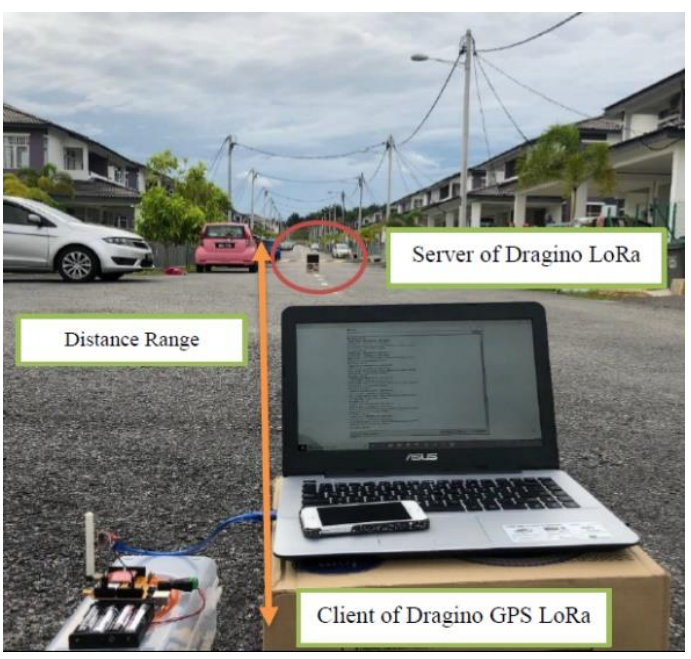

Figure 4. Location of field test

\section{RESULTS AND ANALYSIS}

Serial data in Arduino will generate the reading from LoRa GPS. Figure 5 shows the display in the serial data. The reading shows the LAT, LON, SAT, and PREC which stands for latitude, longitude, satellite, and precision. The precision data shows the relative accuracy of the horizontal position while the satellite indicate the number of available positioning satellite. The reading is displayed in Figure 5. Figure 6 shows the received signal observed from serial data. The reading of receiver consists of latitude and longitude data. Apart from that, received signal strength indicator (RSSI) showing the measurement of the power presented in the received signal was also displayed.

The measurement for the time taken to receive signal and RSSI were observed for every 50 meters as shown in Figure 7. LoRa signal is able to be received within 290 meters of distances. According to LoRa datasheet, LoRa radio transceiver is able to perform transmission for up to 1500 meters of distances. The transmission could be interrupted by obstacles such as cars and buildings. However, LoRa still proven to be the best performance for long range transmission compared to other wireless technology such as Zigbee, radio frequency (RF) and wireless sensor network (WSN) where the transmission is limited within 100 meters of distances [21-25]. The RSSI reading is decreases as distances between transmitter and receiver increases. The performance of RSSI degraded as the distance increases.

Figure 8 shows the analysis of LoRa transceiver battery lifetime. Each LoRa hardware was supplied with alkaline battery AA which is equivalent to 6 volts power supply. It is observed that after 24 hours, the signal transmission still occurred from transmitter to receiver. LoRa proven to be the preferred technology for long hours of operating time.

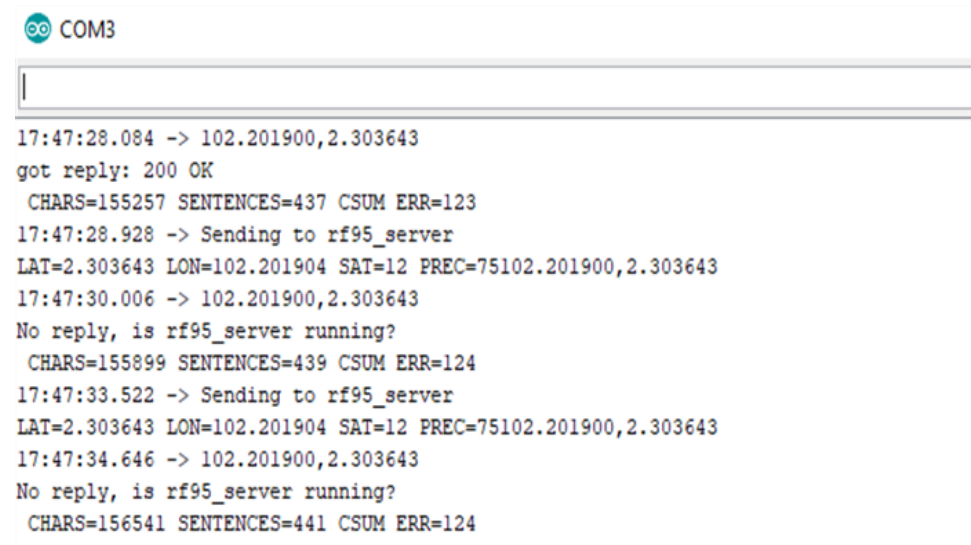

Figure 5. Serial data display the GPS reading at transmitter 


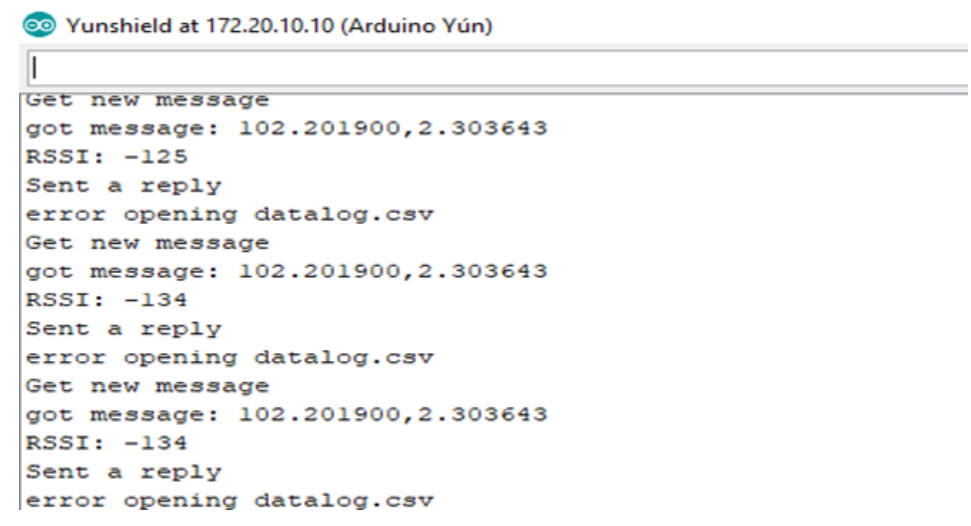

Figure 6. Serial data display the GPS reading at receiver

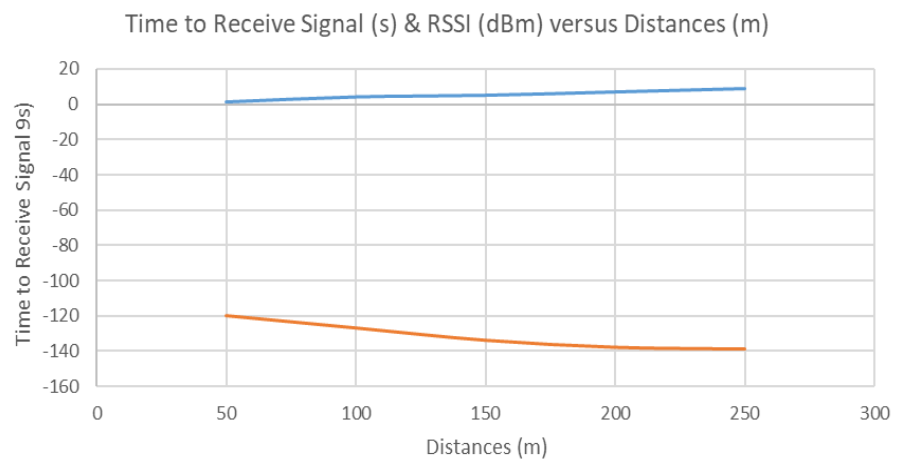

Figure 7. Signal received and RSSI versus distances

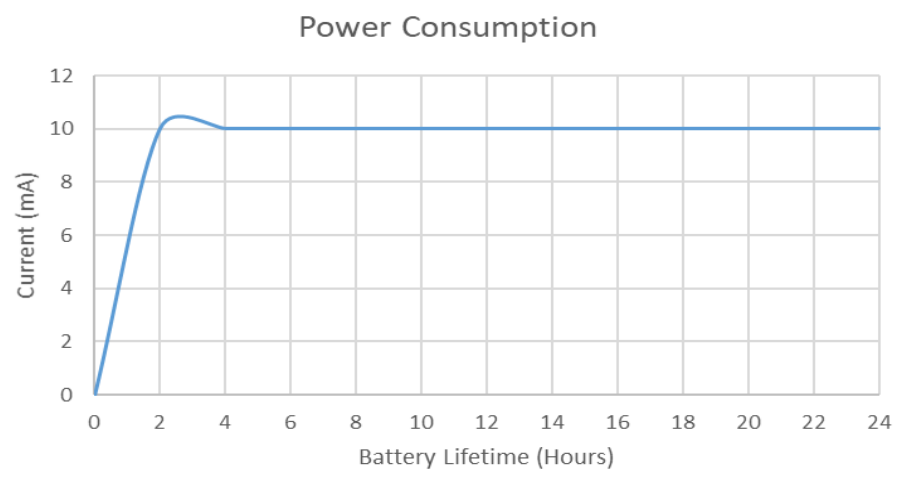

Figure 8. Power consumption

\section{CONCLUSION}

The results prove Dragino LoRa can give network coverage for 290 meters in suburban area with dense residential dwellings. This project could be extended by developing the gateway where the system can be improved by allowing the devices to communicate with an application over the network server. A pole is suggested to be used as a platform to place LoRa as Line of Sight is needed for better reception.

\section{ACKNOWLEDGEMENTS}

The authors would like to acknowledge Centre of Research and Innovation (CRIM), Universiti Teknikal Malaysia Melaka (UTeM) for funding this research and those who give energetic and full support in carrying this research. 


\section{REFERENCES}

[1] M. Centenaro, L. Vangelista, A. Zanella, and M. Zorzi, "Long range communications in unlicensed bands: the rising stars in the IoT and smart city scenarios," IEEE Wireless Communications, vol. 23, no. 5, pp. 60-67, 2016.

[2] J. Petajajarvi, K. Mikhaylov, M. Hamalainen, and J. Iinatti, "Evaluation of LoRa LPWAN technology for remote health and wellbeing monitoring," 2016 10th International Symposium on Medical Information and Communication Technology (ISMICT), Worcester, MA, USA, 2016, pp. 1-5.

[3] S. Liu, C. Xia, and Z. Zhao, "A Low-power Real-time Air Quality Monitoring System Using LPWAN based on LoRa," 2016 13th IEEE International Conference on Solid-State and Integrated Circuit Technology (ICSICT), Hangzhou, 2016, pp. 379-381.

[4] B. C. Fargas, and M. N. Petersen, "GPS-free geolocation using LoRa in low-power WANs," 2017 Global Internet of Things Summit (GIoTS), Geneva, Switzerland, 2017, pp. 1-6.

[5] D. Eridani, E. D. Widianto, R. D. O. Augustinus, and A. Faizal, "Monitoring system in LoRa network architecture using smart gateway in simple LoRa protocol," 2019 International Seminar on Research of Information Technology and Intelligent Systems (ISRITI), Yogyakarta, Indonesia, 2019, pp. 200-204.

[6] P. Edward, A. Muhammad, S. Elzeiny, M. Ashour, T. Elshabrawy, and J. Robert, "Enhancing the Capture Capabilities of LoRa Receivers," 2019 International Conference on Smart Applications, Communications and Networking (SmartNets), Sharm El Sheikh, Egypt, 2019, pp. 1-6.

[7] R. V. Rodriquez, S. Sendra, J. Sendra, J. Lloret, P. Romero-Diaz, and J. L. Garcia-Navas, "Low Cost LoRa based Network for Forest Fire Detection," 2019 Sixth International Conference on Internet of Things: Systems, Management and Security (IOTSMS), Granada, Spain, 2019, pp. 177-184.

[8] J. Jaffar, A. F. A. Malik, M. F. A. Zuhairi, A. A. B. Sajak, M. T. Ismail, "Development of the LoRaWAN-based Movement Tracking System," 2020 14th International Conference on Ubiquitous Information Management and Communication (IMCOM), Taichung, Taiwan, 2020, pp. 1-6.

[9] M. A. I. M. Ariff, Y. L. Then, and F. S. Tay, "Establish Connection Between Remote Areas and City to Improve Healthcare Services," 2019 International Conference on Green and Human Information Technology (ICGHIT), Kuala Lumpur, Malaysia, 2019, pp. 18-23.

[10] S. Sadowski, and P. Petros, "RSSI-Based Indoor Localization with the Internet of Things," IEEE Access, vol. 6, pp. 30149-30161, 2018.

[11] Y. Hou, Z. Liu, and D. Sun, "A novel MAC protocol exploiting concurrent transmissions for massive LoRa connectivity," Journal of Communications and Networks, vol. 22, no. 2, pp. 108-117, 2020.

[12] P. Edward, S. Elzeiny, M. Ashour, and T. Elshabrawy, "On the Coexistence of LoRa- and Interleaved Chirp Spreading LoRa-Based Modulations," 2019 International Conference on Wireless and Mobile Computing, Networking and Communications (WiMob), Barcelona, Spain, 2019, pp. 1-6.

[13] R. Y. Azhari, E. Firmansyah, and A. Bejo, "Simple Protocol Design of Multi-Hop Network in LoRa," 2019 International Seminar on Research of Information Technology and Intelligent Systems (ISRITI), Yogyakarta, Indonesia, 2019, pp. 177-181.

[14] X. Wang, L. Kong, L. He, and G. Chen, "mLoRa: A Multi-Packet Reception Protocol in LoRa networks," 2019 IEEE 27th International Conference on Network Protocols (ICNP), Chicago, IL, USA, 2019, pp. 1-11.

[15] L. Leonardi, F. Battaglia, and L. Lo Bello, "RT-LoRa: A Medium Access Strategy to Support Real-Time Flows Over LoRa-Based Networks for Industrial IoT Applications," IEEE Internet of Things Journal, vol. 6, no. 6, pp. 10812-10823, 2019.

[16] M. H. Dwijaksara, W. S. Jeon, and D. G. Jeong, "Multihop Gateway-to-Gateway Communication Protocol for LoRa Networks," 2019 IEEE International Conference on Industrial Technology (ICIT), Melbourne, VIC, Australia, 2019, pp. 949-954.

[17] W. Wu, Y. Li, Y. Zhang, B. Wang, and W. Wang, "Distributed Queueing-Based Random Access Protocol for LoRa Networks," IEEE Internet of Things Journal, vol. 7, no. 1, pp. 763-772, 2020.

[18] S. Opipah, H. Qodim, D. Miharja, E. A. Zaki, and T. Juhana, "Prototype Design of Smart Home Base on LoRa," 6th International Conference on Wireless and Telematics (ICWT), Yogyakarta, Indonesia, 2020.

[19] F. A. R. M. Wildan, E. A. Z. Hamidi, T. Juhana, "The Design of Application for Smart Home Base on LoRa," 6th International Conference on Wireless and Telematics (ICWT), Yogyakarta, Indonesia, 2020.

[20] A. B. Bababe, K. J. Ashish, K. Rajiv, "LoRa Based Intelligent Home Automation System," International Journal of Engineering and Advanced Technology (IJEAT), vol. 6, no. 3, pp. 88-92, 2017.

[21] N. Hashim, M. A. H. A. Razak, and F. Idris, "Home Security System Using ZigBee," Jurnal Teknologi (Sciences \& Engineering), vol. 74, no. 10, pp. 29-34, 2015.

[22] F. Idris, N. Hashim, A.F. Kadmin, and L. B. Yee, "Intelligent Fire Detection and Alert System using LabVIEW," International Journal of Electrical and Computer Engineering (IJECE), vol. 9, no. 3, pp 1842-1849, 2019.

[23] N. Hashim, S. H. S. Ariffin, F. Yunus, F. Idris, and N. Fisal, "Deployment of Optimized Algorithm for MPEG-4 over Wireless Sensor Network," ARPN Journal of Engineering and Applied Sciences, vol. 9, no. 7, pp. 1035-1041, 2014.

[24] N. Hashim, N. F. A. M. Azmi, F. Idirs, and N. Rahim, "Smartphone activated door lock using WiFi," ARPN Journal of Engineering and Applied Sciences, vol. 11, no. 5, pp. 3309-3312, 2016.

[25] N. Hashim, N. Noordin, F. Idris, S. N. I. M. Yusoff, and M. Zahari, "IoT blood pressure monitoring system," Indonesian Journal of Electrical Engineering and Computer Science (IJEECS), vol. 19, no. 3, pp. 1384-1390, 2020. 


\section{BIOGRAPHIES OF AUTHORS}
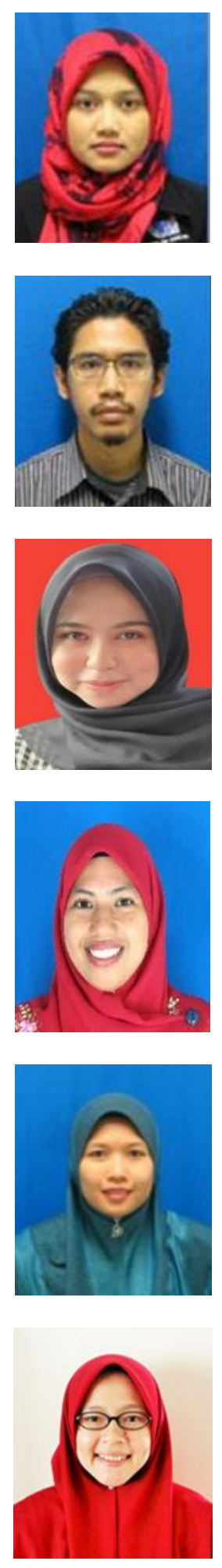

Norlezah Hashim obtained her first degree in 2006 from University of Malaya and her master degree from Universiti Teknologi Malaysia in 2014. In the past, she worked in Panasonic as an R\&D engineer. Currently she is serving UTeM as a lecturer in Faculty of Electrical \& Electronic Engineering Technology. She published several engineering and technical works on wireless communication and wireless sensor network.

Fakrulradzi Idris received the B.Eng. and the M.Eng. Degrees from Universiti Teknologi Malaysia in 2007 and 2008 respectively. He received the PhD degree from The University of Manchester, U.K in 2018. He is a senior lecturer in Faculty of Electronic and Computer Engineering (FKEKK), Universiti Teknikal Malaysia Melaka (UTeM). His research interests include Device-to-Device (D2D) communications, Non-Orthogonal Multiple Access (NOMA) and $5 \mathrm{G}$ networks.

Tuan Nur Anisa was graduated in Bachelor Degree in Electronic Engineering (Telecommunications) from Universiti Teknikal Malaysia Melaka (UTeM), Malaysia in 2019.

Siti Halma Johari received the Bachelor Degree in Electronic Engineering (Industrial Electronics) from Universiti Teknikal Malaysia Melaka (UTeM) in 2005 and Master of Engineering in Control \& Automation from University of Malaya (UM), Malaysia. She was a Test Engineer in Venture Electronic Services from 2005 to 2010 under Agilent Technologies Department. From 2010 to 2014, she had been a Teaching Engineer at UTeM and then, in 2015, she was appointed as a Lecturer. She is currently a $\mathrm{PhD}$ student in photonic research under Nanotechnology and Sensor Laboratory at Faculty of Engineering, University Malaya.

Rozilawati Mohd Nor received the first B.Eng. degree in electrical engineering (control, instrumentation and automation), in 2011, and the M.Sc. degree in electrical engineering from Universiti Teknikal Malaysia Melaka, 2015. She is currently a Lecturer with the Faculty of Electrical and Electronic Engineering Technology, Universiti Teknikal Malaysia Melaka. Her major field of study is in control system design and application. She is a member of Board of Engineers Malaysia (BEM) and Malaysian Board of Technologist (MBOT)

Norfariza Ab Wahab. Melaka, Malaysia, received B.Eng (2009) and M.Eng Degree (2012) and Master from Nagaoka University of Technology, Nigata, Japan from Department of Mechanical. She graduated as $\mathrm{PhD}$ student at Tokyo University of Agriculture, Japan in 2015. She is currently working as a senior lecturer in Faculty of Mechanical and Manufacturing Engineering Technology (FTKMP), Universiti Teknikal Malaysia Melaka (UTeM). His research interests include advanced machining, small scale product development, CAD/CAE. 